\title{
SYNERGISTIC ANTICANDIDAL ACTIVITY OF TWO TERMINALIA SPECIES WITH POLYENE AND AZOLE GROUP OF ANTIBIOTICS AGAINST MULTIDRUG-RESISTANT CLINICAL ISOLATES OF CANDIDA
}

\author{
TEJAS RATHOD, HEMALI PADALIA, SUMITRA CHANDA*
}

Department of Biosciences (UGC-CAS), Phytochemical, Pharmacological and Microbiological Laboratory, Saurashtra University, Rajkot - 360 005, Gujarat, India. Email: svchanda@gmail.com

Received: 28 July 2017, Revised and Accepted: 03 October 2017

\section{ABSTRACT}

Objectives: The aim of the present study was to evaluate synergistic anticandidal activity of two Terminalia species with polyene and azole group of antibiotics against multidrug-resistant clinical isolates of Candida.

Methods: The synergistic effect of ethanol extract of leaf of Terminalia cattapa. and Terminalia chebula with six standard antibiotics, namely, amphotericin B, nystatin, fluconazole (FLC), ketoconazole (KT), clotrimazole (CC), and itraconazole (IT) was evaluated against the clinical isolates by disk diffusion assay.

Results: The synergistic activity of the antibiotics with ethanol extract of T. chebula was better than with that of T. cattapa. T. chebula ethanol extract increased the anticandidal effect of azole antibiotics FLC and KT, while it had a less synergistic effect on CC and IT.

Conclusion: Therefore, FLC/KT plus ethanol extract of T. chebula can be an interesting and alternative source of anticandidal agent against Candida species.

Keywords: Terminalia chebula, Terminalia catappa, Antibiotics, Fluconazole, Synergistic activity, Anticandidal agent.

(c) 2018 The Authors. Published by Innovare Academic Sciences Pvt Ltd. This is an open access article under the CC BY license (http://creativecommons. org/licenses/by/4. 0/) DOI: http://dx.doi.org/10.22159/ajpcr.2018.v11i1.21664

\section{INTRODUCTION}

Infections due to opportunistic fungi are occurring at an alarming rate. The incidence of fungal infection is rising not only in hospital environment but also in normal population. Fungal infections are the $4^{\text {th }}$ leading cause of hematogenous infections, and the most common fungi are Candida species [1], namely, Candida albicans, Candida tropicalis, Candida glabrata, Candida parapsilosis, Candida stellatoidea, Candida krusei, and Candida kyfer; C. albicans being the most important one [2]. The range of fungal infections varies from colonization of mucosa to invasive deadly infections. Candida infections are treated with antifungal drugs such as amphotericin B (AMP), nystatin (NYS), itraconazole (IT), fluconazole (FLC), ketoconazole (KT), econazole, miconazole, clotrimazole (CC), and tioconazole. However, overuse of these drugs causes many side effects, including hypersensitivity, allergic reactions, immune suppression, and results in resistant strains $[3,4]$. These problems are also positively impacted by diseases such as cancer, diabetes, and AIDS [5,6]. The high cost, toxic effects, and increase in resistant strains compel the researchers to search for herbal drugs with fewer side effects or new approaches such as combination therapy or synergistic approach which results in additive or synergistic effect. The synergistic approach increases the spectrum of activity, decreases the risk of emergence of resistant strains, and deletes the harmful effects of immunotherapy with chemical agents [7]. The increasing recognition and importance of fungal infections with respect to resistance to antifungal drugs have stimulated the search for safe, natural therapeutic alternatives which are more effective, eco-friendly, and less toxic. It is essential to search for antifungals belonging to a wide range of structural classes selectively acting on different targets with less lateral effects. The best opportunity is natural plant extracts which can be tried individually or in combination. Plant extracts showed promising antibacterial and antifungal activities [8,9]. The concept of using single drugs to treat infections is changing. When drugs are used in combination, the phytochemicals present in them exert different mode of action which increases the effectiveness of their antimicrobial therapy $[10,11]$. Thus, synergistic therapy may be the answer to the increase in fungal resistance to the existing antifungal drugs.

Terminalia chebula Retz. and Terminalia catappa L. belong to the family Combretaceae. They are traditionally used to treat many diseases and disorders. There are many reported activities for both these plants. Some of the reported activities of T. chebula are analgesic activity, antifertility activity, anti-inflammatory activity, antimicrobial activity, antioxidant activity, nephroprotective activity, and plasmid curing activity while that of T. catappa are allelopathic activity, antibacterial activity, anticlastogenic activity, antioxidant and antimicrobial activity, antiulcer activity, and molluscicidal activity,. [12]. However, there are no reports till date on the anticandidal activity of these plants against clinical isolates of Candida. In the present work, we evaluated the anticandidal activity of ethanol extract of leaf of $T$. chebula and T. catappa against 19 clinical isolates of Candida. We also evaluated the synergistic effect of ethanol extract of leaf of these plants with six standards antibiotics, namely, AMP, NYS, FLC, KT, CC, and IT against the clinical isolates.

\section{METHODS}

Plant materials

The leaves of T. chebula Retz and T. catappa L. were collected from Jamnagar, Gujarat, India. The plant was compared with voucher specimen (voucher specimen No. PSN 291 and PSN292) deposited at the Department of Biosciences, Saurashtra University, Rajkot, Gujarat, India. The leaves were thoroughly washed with tap water and airdried under shade. The dried leaves parts were homogenized to a fine powder and stored in airtight bottles which were later used for solvent extraction. 


\section{Extraction}

The dried powder of leaf was extracted by the cold percolation method [13]. Ten grams of dried powder was added to $100 \mathrm{ml}$ of hexane in a conical flask, which was plugged with cotton wool and kept on a rotary shaker at $120 \mathrm{rpm}$ for $24 \mathrm{~h}$. After $24 \mathrm{~h}$, the extract was filtered with 8 layers of muslin cloth and centrifuged at $5000 \mathrm{rpm}$ for $10 \mathrm{~min}$. Supernatant was collected, and the solvent was evaporated. The residue was then added to $100 \mathrm{ml}$ of ethanol in a conical flask, which was plugged with cotton wool and kept on a rotary shaker at $120 \mathrm{rpm}$ for $24 \mathrm{~h}$. After $24 \mathrm{~h}$, the extract was filtered with 8 layers of muslin cloth and centrifuged at $5000 \mathrm{rpm}$ for $10 \mathrm{~min}$. The supernatant was collected, and the solvents were evaporated; the dry extract was stored at $4^{\circ} \mathrm{C}$ in airtight bottles.

\section{Antibiotics used in the study}

The six different antibiotics (Hexa Disc): AMP (100 units/disc), NYS (100 units/disc), KT (30 mcg/disc), FLC (10 mcg/disc), CC (10 mcg/disc), andIT (30 mcg/disc) were used in the study.

\section{Fungal strains}

Fifty clinical strains of Candida spp. were collected from various microbiological laboratories of Rajkot, Gujarat, India. Most of the strains were isolated from patients with skin infections and some from a urine sample. The isolates were cultured on Sabouraud dextrose agar medium with chloramphenicol under aerobic conditions within a temperature range of $28^{\circ} \mathrm{C}$. The isolates were identified as Candida species on the basis of some biochemical tests such as blastospore/ chlamydospore formation, color of colony on HiChrome Candida differential agar, carbohydrate assimilation test (sucrose, mannose, lactose, and malate), and negative absorption (urea and nitrate). The susceptibility test revealed 19 isolates as multidrug-resistant (MDR), and hence, these 19 isolates were used for further study. The 19 isolates are named as C1, C2, C3, C5, C6, C12, C13, C14, C15, C18, C21, C22, C23, C26, C30, C41, C42, C43, and C44.

\section{Synergistic anticandidial assay}

Synergistic anticandidial activity of the T. chebula and T. catappa leaf extracts with antibiotics (AMP, NYS, KT, FLC, CC, and IT) were evaluated using disc diffusion method [14]. The Petri plates were prepared by pouring $20 \mathrm{ml}$ Sabouraud dextrose agar seeded with $200 \mu \mathrm{l}$ test culture containing $1 \times 10^{8} \mathrm{cfu} / \mathrm{ml}$ as McFarland 0.5 turbidity standard. Plates were allowed to solidify. Standard antibiotics paper discs (6 mm) were impregnated with $20 \mu \mathrm{l}$ of T. chebula and T. catappa leaf extracts $(20 \mathrm{mg} / \mathrm{ml})$ dissolved in dimethyl sulfoxide (DMSO) separately. The sterile paper discs were impregnated with $20 \mu \mathrm{l}$ of $T$. chebula and T. catappa leaf extracts (in DMSO) separately. All the discs were allowed to saturate for $30 \mathrm{~min}$ and were placed on the surface of the agar plates which had previously been inoculated with Candida isolates, respectively. All plates were incubated for $48 \mathrm{~h}$ at $28^{\circ} \mathrm{C}$. Results were recorded by measuring the zone of inhibition appearing around the discs. All the tests were performed in triplicate, and the mean values are presented.

\section{Increase in fold area (IFA)}

IFA was calculated as $\left(\mathrm{B}^{2}-\mathrm{A}^{2}\right) / \mathrm{A}^{2}$

Where A - inhibition zone for Antibiotics and B - inhibition zone for plant extract + antibiotics.

\section{RESULTS}

In disc diffusion method, the ethanol extract of $T$. chebula and T. catappa, two polyene antibiotics, namely, AMP and NYS, and four azole antibiotics, namely, KT, FLC, CC, and IT were evaluated for their antifungal activity against 19 Candida spp. The ethanol extract of both Terminalia species did not show any antifungal activity against any of the 19 clinical Candida isolates. Both polyene antibiotics showed a greater zone of inhibition as compared to azole antibiotics. Maximum zone of inhibition was shown by NYS (18.89) and minimum by IT (6.74). However, all the six antibiotics showed a greater zone of inhibition than ethanol extract of T. catappa and T. chebula (Figs. 1b-6b).
The synergistic antifungal activity of T. chebula and T. catappa ethanol extract with 6 antibiotics (AMP, NYS, KT, FLC, CC, and IT) against 19 clinical isolates of Candida is given in Figs. 1a-6a. IFA values are given in Table 1. The antifungal activity of ethanol extract of both plants, antibiotics AMP, NYS, and their synergistic activity, i.e. ethanol extract of plant plus antibiotic AMP and NYS against all 19 clinical Candida isolates are given in Figs. $1 \mathrm{a}$ and $2 \mathrm{a}$, and their mean zone of inhibition is given in Figs. $1 \mathrm{~b}$ and $2 \mathrm{~b}$, respectively. Both these antibiotics did not exhibit any significant synergistic activity. T. chebula ethanol extract with both the antibiotics exhibited synergistic activity against only 3 isolates while T. catappa exhibited synergistic activity against 3 and 7 isolates with AMP and NYS, respectively. Maximum IFA value was 5.67 and 3.34 against C12 by ethanol extract of T. catappa and T. chebula, respectively, with AMP (Fig. 1 and Table 1); while it was 5.67 and 8.51 with NYS (Fig. 2 and Table 1).

The antifungal activity of T. chebula and T. catappa ethanol extract, 4 azole antibiotics KT, FLC, CC and IT, and their synergistic activity against all 19 clinical isolates are given in Figs. 3a-6a, and their mean zone of inhibition is given in Figs. 3b-6b, respectively. The mean zone of inhibition of antibiotic KT against 19 clinical isolates was 7.58. Both the plant extracts showed significant synergistic activity. The mean synergistic activity of T. chebula ethanol extract with KT was 12.21 while that of T. catappa was 13.16 (Fig. 3b). T. chebula ethanol extract showed synergistic activity against 17 isolates while T. catappa ethanol extract showed synergistic activity against 13 isolates. Maximum IFA value was 8.5 against isolate C42 by T. catappa extract and 4.44 against isolate $\mathrm{C} 3$ by $T$. chebula extract (Table 1). The IFA value was more with T. catappa extract than $T$. chebula extract (Table 1).

The antifungal activity with antibiotic FLC is given in Fig. 4. The ethanol extract of T. chebula with FLC showed synergistic activity against all the 19 isolates while T. catappa showed activity only against 8 isolates. The IFA values of T. chebula ranged from 0.94 to 4.84 (Table 1). Maximum IFA value was 4.84 against isolate C42. Maximum IFA value was 5.25 against isolate $\mathrm{C} 1$ and $\mathrm{C} 26$ by T. catappa extract.

The trend of antifungal activity with azole antibiotic CC was similar to that of FLC (Fig. 5). Mean synergistic activity (i.e. mean zone of inhibition) of T. chebula and T. catappa was 11.36 and 9.66, respectively.

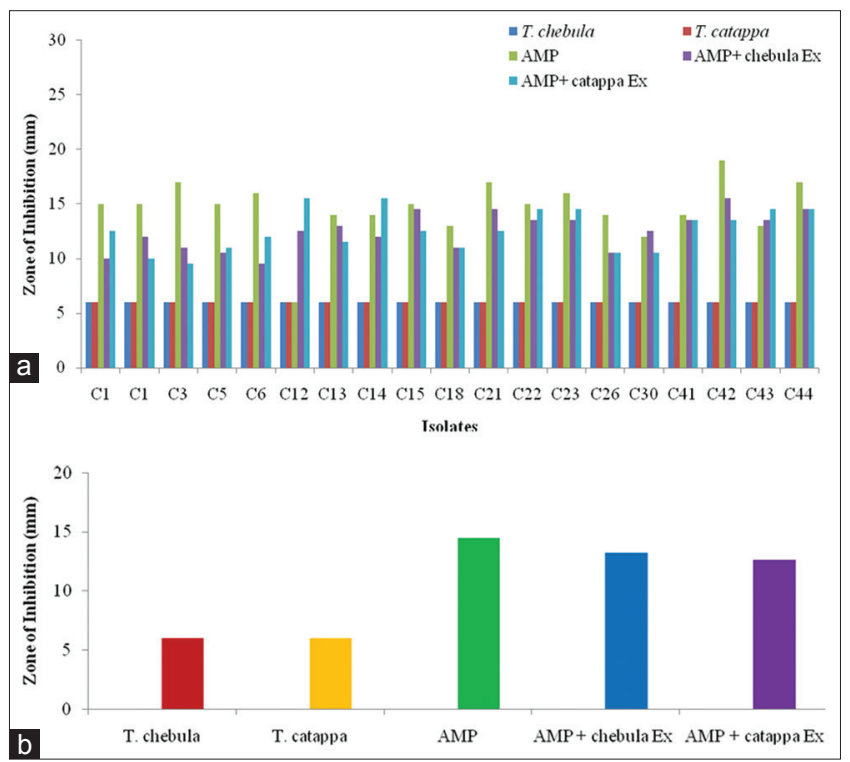

Fig. 1: (a) Synergistic anticandidal activity of Terminalia chebula and Terminalia catappa with amphotericin B (AMP) against Candida isolates. (b) Mean values of zone of inhibition of plant extracts and antibiotic alone and in combination against Candida isolates 


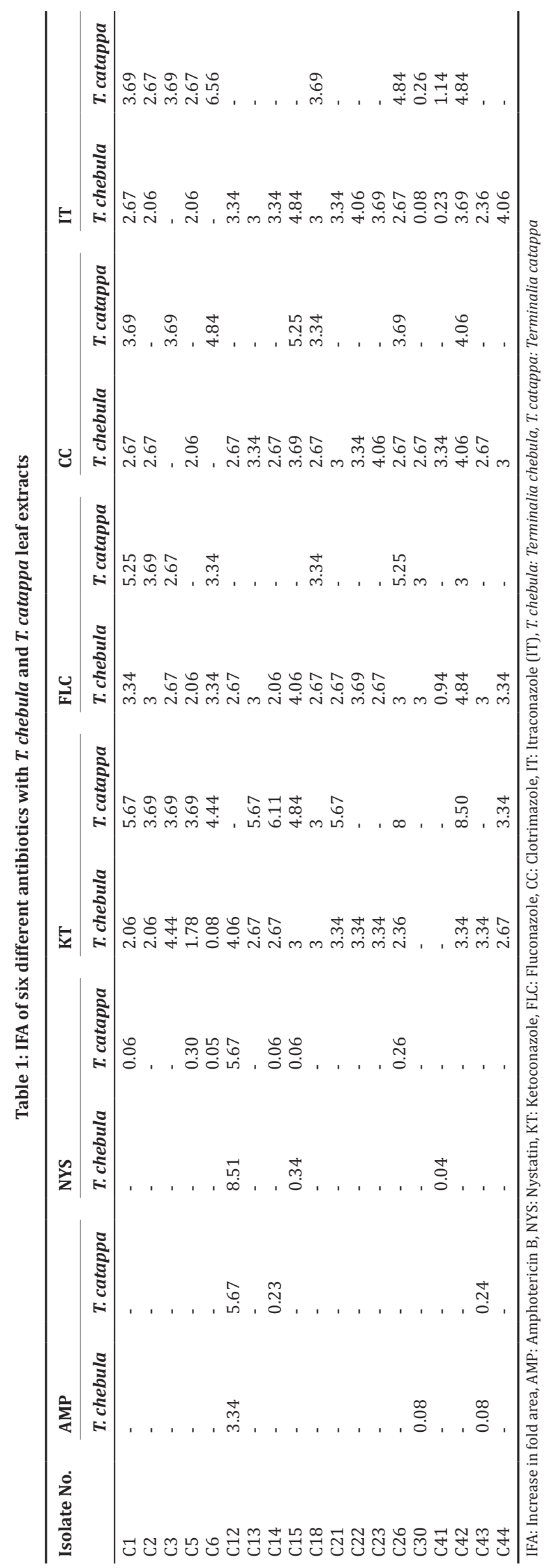

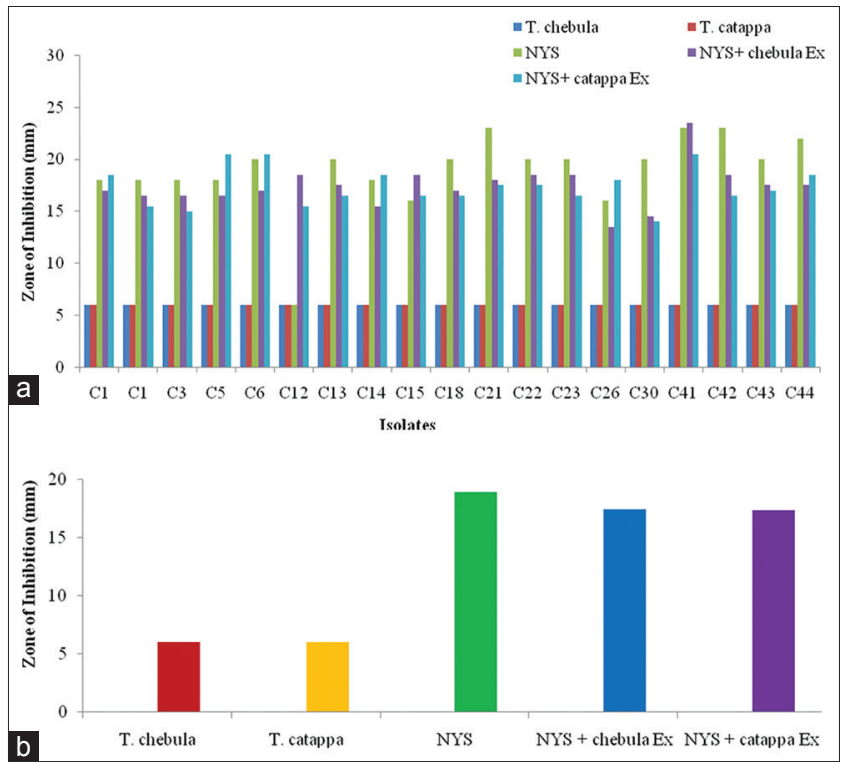

Fig. 2: (a) Synergistic anticandidal activity of Terminalia chebula and Terminalia catappa with nystatin (NYS) against Candida isolates. (b) Mean values of zone of inhibition of plant extracts and antibiotic NYS alone and in combination against Candida isolates

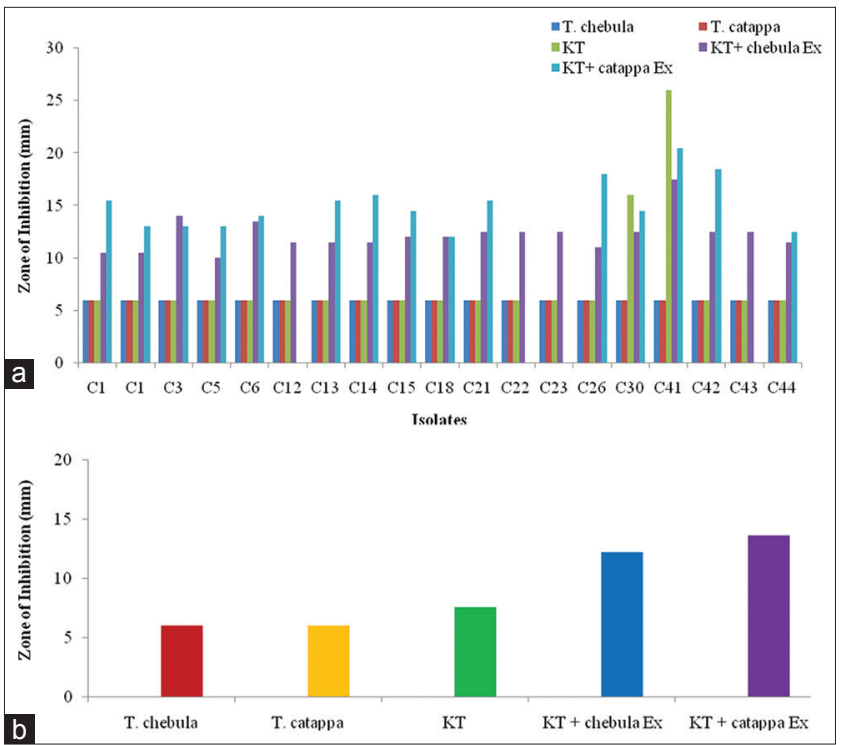

Fig. 3: (a) Synergistic anticandidal activity of Terminalia chebula and Terminalia catappa with ketoconazole (KT) against Candida isolates. (b) Mean values of zone of inhibition of plant extracts and antibiotic KT alone and in combination against Candida isolates

The former showed inhibitory activity against 17 isolates while the later showed activity against 7 isolates. IFA value of 4.06 was shown by T. chebula against isolates C23 and C42; IFA value of 5.25 was shown by T. catappa extract against isolate C15.

The antifungal activity of antibiotic IT was almost same as that of other azole antibiotics. The mean synergistic activity and IFA values were also similar to other azole antibiotics. The mean synergistic activity of T. chebula was 11.79 while that of T. catappa was 10.29 while that of antibiotic IT alone was only 6.74. Maximum IFA value was 4.84 and 6.56 against isolate $\mathrm{C} 15$ and $\mathrm{C} 6$ by T. chebula and T. catappa, respectively (Fig. 6 and Table 1). 


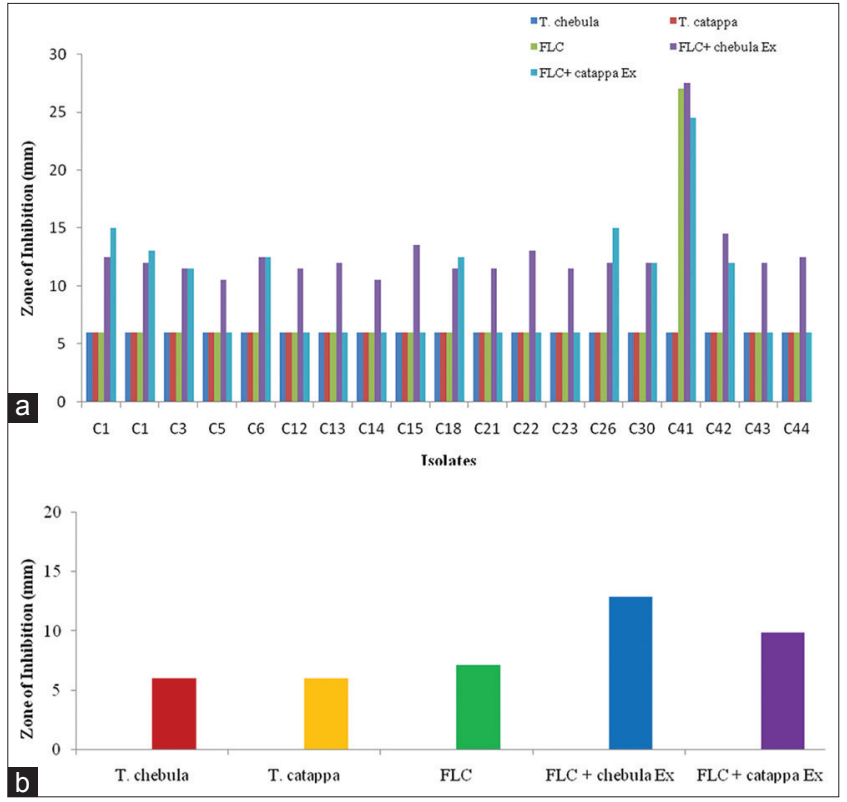

Fig. 4: (a): Synergistic anticandidal activity of Terminalia chebula and Terminalia catappa with fluconazole (FLC) against Candida isolates. (b) Mean values of zone of inhibition of plant extracts and antibiotic FLC alone and in combination against Candida isolates

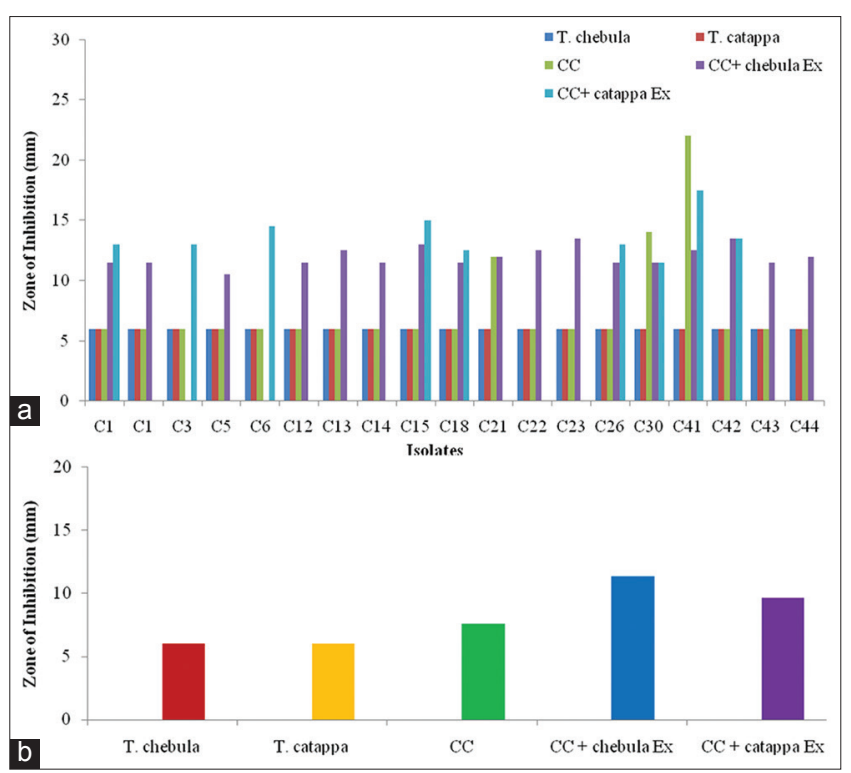

Fig. 5: (a) Synergistic anticandidal activity of Terminalia chebula and Terminalia catappa with clotrimazole (CC) against Candida isolates. (b) Mean values of zone of inhibition of plant extracts and antibiotic clotrimazole alone and in combination against Candida isolates

\section{DISCUSSION}

There is a dramatic increase in resistant antifungal strains, which is the result of widespread and repeated use of antibiotics and antifungal agents for a longer duration. Several Candida species, namely, C. albicans, C. tropicalis, C. glabrata, C. parapsilosis, C. stellatoidea, C. krusei, and C. kyferare becoming resistant to AMP, a polyene antibiotic [15], and azole resistant [16] which is worrisome and threatening. Thus, gradually the antibiotic therapy failed which prompts for new line of treatment. Great efforts were made to identify natural agents to combat these opportunistic infections. Medicinal plant extracts are

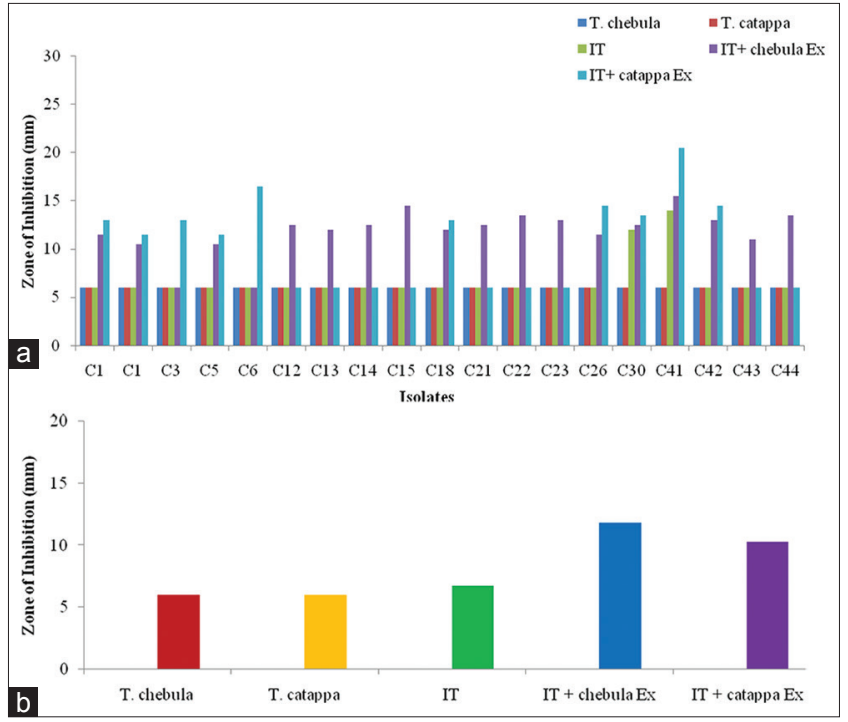

Fig. 6: (a) Synergistic anticandidal activity of $T$ Terminalia chebula and Terminalia catappa with itraconazole (IT) against Candida isolates. (b) Mean values of zone of inhibition of plant extracts and antibiotic IT alone and in combination against Candida isolates

well known for their antibacterial and antifungal activities [17-19]. The antifungal activity of some plant extracts against Candida spp. is also reported $[20,21]$. The antimicrobial activities of the plants are attributed to their secondary metabolites $[22,23]$. However, the most promising approach is combination therapy or synergistic approach.

In the present work, the ethanol extract of T. chebula and T. cattappa leaf extract and 6 antibiotics alone and in combination, i.e., plant extract plus antibiotic was evaluated against 19 clinical isolates of Candida. Both the plant ethanol extracts did not show any antifungal activity. The zone of inhibition of both AMP and NYS and both polyene antibiotics alone was greater than all the four azoles (KT, FLC, CC, and IT) antibiotics. This differential inhibition might be due to different mechanism of action of both classes of antifungals. Ergosterol is an integral component of fungal cell membrane. Azole antibiotics inhibit the biosynthesis of ergosterol by inhibiting cytochrome P-450-dependent enzyme lanosterol 14-alphademethylase which results in blocking of proliferation of Candida species. On the other hand, polyene antibiotics interact with ergosterol to form channels which result in leakage of vital cytoplasmic components from inside the fungal cells to outside leading to cell death.

In combination therapy also, both classes of antifungal depicted different results. AMP and NYS did not show any synergistic activity while all the four azole antibiotics showed good synergistic activity. The synergistic activity of the antibiotics with ethanol extract of T. chebula was better than with that of T. cattapa. Among the four azole antibiotics, KT and FLC showed better synergistic activity than CC and IT. Maximum mean zone of inhibition was with FLC in combination with T. chebula extract $(12.86 \mathrm{~mm})$ followed by KT $(12.21 \mathrm{~mm})$; this combination showed synergistic activity against all the 19 and 17 clinical isolates of Candida, respectively. The synergistic activity of S. khuzistanica ethanol extract with antibiotic KT was reported by Mahboubi and Kazempour [24] while Avijgan et al. [25]reported synergistic activity of E. platyloba ethanol extract with IT and FLC. Antagonistic effect was reported against CC and miconazole by the same authors, while we report no synergistic effect against AMP and NYS.

The synergistic activity of FLC and KT may be attributed to the high phenolic content present in T. chebula. The synergistic activity of plant extracts and antibiotics is reported by many other researchers [26-29]. The combination of azole antibiotics, especially FLC and KT, with 
ethanol extract of T. chebula can be an alternative way of minimizing side effects of the antibiotics, since it leads to significant synergistic effect, reducing the dose which is necessary for therapeutic use. Endo et al. [30] also reported similar results from pomegranate peels. The plant extracts alone had no antifungal efficiency, but in combination with antibiotics, they could enhance or rather show synergistic effect, similar to the results of present work. The stem bark and leaf extracts of L. paniculata had no antifungal activity, but in combination with antibiotic, a significant synergistic effect was observed [31]. Therefore, FLC/KT plus ethanol extract of T. chebula can be an interesting and alternative source of treatment for Candida caused infections.

\section{CONCLUSION}

This study suggests that plant extracts alone did not show antifungal activity, but in combination with antibiotics, enhanced antifungal activity was demonstrated. The combination of $T$. chebula leaf extract and FLC/KT can be used as a new source of an antifungal agent against MDR Candida species.

\section{ACKNOWLEDGMENT}

The authors would like to thank the Department of Biosciences (UGC-CAS), Saurashtra University, Rajkot, Gujarat, India, for providing excellent research facilities. The authors Mr. Tejas Rathod acknowledges the award of Senior Research Fellowship from UGC, New Delhi, India, and Ms. Hemali Padalia is thankful to UGC, New Delhi, India, for providing Junior Research Fellowship.

\section{REFERENCES}

1. Martins N, Barros L, Henriques M, Silva S, Ferreira IC. Activity of phenolic compounds from plant origin against Candida species. Ind Crop Prod 2015;74:648-70.

2. Tsai PW, Chen YT, Hsu PC, Lan CY. Study of Candida albicans and its interactions with the host: A mini review. Biomedicine 2013;3:51-64.

3. Mukherjee PK, Saritha GS, Suresh B. Antimicrobial potential of two different Hypericum species available in India. Phytother Res 2002;16:692-5.

4. Yang YL, Cheng HH, Ho YA, Hsiao CF, Lo HJ. Fluconazole resistance rate of Candida species from different regions and hospital types in Taiwan. J Microbiol Immunol Infect 2003;36:187-91.

5. Jordà-Marcos R, Alvarez-Lerma F, Jurado M, Palomar M, NollaSalas J, León MA, et al. Risk factors for candidaemia in critically ill patients: A prospective surveillance study. Mycoses 2007;50:302-10.

6. Shen YZ, Qi TK, Ma JX, Jiang XY, Wang JR, Xu QN, et al. Invasive fungal infections among inpatients with acquired immune deficiency syndrome at a Chinese university hospital. Mycoses 2007:50:475-80.

7. Putheti R, Okigbo RN. Effects of plants and medicinal plant combinations as anti-infective. Afr J Pharm Pharmacol 2008;2:130-5.

8. Vanga S, Pingili M, Tharigoppula S. Phytochemical screening and evaluation of antifungal activity of gall extracts of Quercus infectoria. Int J Pharm Sci Res 2017;8:3010-13.

9. Hussain A, Zaman MK, Ramteke AM. Antibacterial activity of trunk bark of Alstonia scholaris. Asian J Pharm Clin Res 2010;3:46-7.

10. Rathod T, Padalia H, Chanda S. The potential of plant extracts against multidrug resistant Candida species-a review. In: Mendez-Vilas A, editor. The Battle against Microbial Pathogens: Basic Science, Technological Advances and Educational Programs. Badajoz, Spain: FORMATEX Research Center; 2015. p. 246-56.

11. Hishobkar SM, Urolagin DK, Ashish C, Maski S. Evaluation of synergestic antimicrobial effect of Anogeissus latifolia and Glycerrhiza glabra extract. Int J Pharm Pharm Sci 2010;2:158-9.

12. Ram J, Moteriya P, Chanda S. Phytochemical screening and reported biological activities of some medicinal plants of Gujarat region. J Pharmacogn Phytochem 2015;4:192-8.
13. Parekh J, Chanda S. In vitro antibacterial activity of the crude methanol extract of Woodfordia fruticosa Kurz. Flower (Lythraceae). Braz J Microbiol 2007;38:204-7.

14. Rakholiya K, Chanda S. In vitro interaction of certain antimicrobial agents in combination with plant extracts against some pathogenic bacterial strains. Asian Pac J Trop Biomed 2012;2:S876-80.

15. Negri M, Silva S, Breda D, Henriques M, Azeredo J, Oliveira R. Candida tropicalis biofilms: Effect on urinary epithelial cells. Microb Pathog 2012;53:95-9.

16. Jiang C, Dong D, Yu B, Cai G, Wang X, Ji Y, et al. Mechanisms of azole resistance in 52 clinical isolates of Candida tropicalis in China. J Antimicrob Chemother 2013;68:778-85.

17. Bora L. Anticandidal activity of medicinal plants and Pseudomonas aeruginosa strains of clinical specimens. J Microbiol Immunol Infect 2016;49:276-80.

18. Siebra AL, Oliveira LR, Martins AO, Sibera DC, Albuquerque RS, Lemos IC, et al. Potentiation of antibiotic activity by Passiflora cincinnata Mast. Front of strains Staphylococcus aureus and Escherichia coli. Saudi J Biol Sci 2016. DOI: org/10.1016/j.sjbs.2016.01.019.

19. Rakholiya K, Vaghela P, Rathod T, Chanda S. Comparative study of hydroalcoholic extracts of different parts of Momordica charantia L. Against food spoiling microorganisms. Indian J Pharm Sci 2014:139:121-34.

20. Rahmayanti F, Suniarti DF, Masúd ZA, Bachtiar BM, Wimardhani YS, Subita GP. Ethyl acetate fraction of Garcinia mangostana Linn pericarp extract: Anti-Candida albicans and epithelial cytotoxicity. Asian J Pharm Clin Res 2016;9:357-60.

21. Regis AS, Gabriel JJ. Antifungal activity of Cyanotis axillaris (1.) d. DON EX sweet against opportunistic fungal strains. Int J Pharm Pharm Sci 2017;9:140-3.

22. Poojary MM, Vishnumurthy KA, Adhikarin AV. Extraction, characterization and biological studies of phytochemicals from Mammea suriga. J Pharm Anal 2015;5:182-9.

23. Wong KY, Vikram P, Chiruvella KK, Mohammed A. Phytochemical screening and antimicrobial potentials of Borreria sps. (Rubiaceae). J King Saud Uni Sci 2015;27:302-11.

24. Mahboubi M, Kazempour N. The anti-candidal activity of Satureja khuzistanica ethanol extract against clinical isolate of C. albicans. J Mycol Med 2016;26:6-10.

25. Avijgan M, Mahboubi M, Nasab MM, Nia EA, Yousefi H. Synergistic activity between Echinophora platyloba DC ethanolic extract and azole drugs against clinical isolates of Candida albicans from women suffering chronic recurrent vaginitis. J Mycol Med 2014;24:112-6.

26. Olajuyigbe OO, Afolayan AJ. Synergistic interactions of methanolic extract of Acacia mearnsii De Wild. With antibiotics against bacteria of clinical relevance. Int J Mol Sci 2012;13:8915-32.

27. Chanda S, Rakholiya K, Dholakia K, Baravalia Y. Antimicrobial, antioxidant and synergistic property of two nutraceutical plants: Terminalia catappa L. and Colocasia esculentum L. Turk J Biol 2013;37:81-91.

28. Elalfi ZA, Fakim AG, Mahomoodally F. Antimicrobial, antibiotic potentiating activity and phytochemical profile of essential oils from exotic and endemic medicinal plants of maurities. Indus Crops Prod 2015;71:197-204.

29. Padalia H, Chanda S. Antimicrobial efficacy of different solvent extracts of Tagetes erecta L. flower, alone and in combination with antibiotics. Appl Microbiol 2015;1:1-10.

30. Endo EH, Cortez DA, Ueda-Nakamura T, Nakamura CV, Dias Filho BP. Potent antifungal activity of extracts and pure compound isolated from pomegranate peels and synergism with fluconazole against Candida albicans. Res Microbiol 2010;161:534-40.

31. Júnior JT, Morais SM, Martins CG, Vieira LG, Morais-Braga MF, Carneiro JN, et al. Phytochemical analysis and modulation of antibiotic activity by Luehea paniculata Mart. and Zucc. (Malvaceae) in multi-resistant clinical isolates of Candida Spp. Biomed Res Int 2015;2015:1-10. 